\title{
THE PRESENT POSITION OF FOREST MANAGE- MENT PROTECTION AND SILVICULTURE IN CANADA
}

\author{
By ANgus Graham
}

T $\mathrm{T}$ is a matter of common experience that Canadian forestry enjoys an excessively bad reputation, both among reformers at home and technical observers from abroad. Moreover, the stream of reprobation that is poured upon our methods is at once so loud, so unanimous, and so authoritative as to forbid any easy assumption that it may be due, in the case of visitors, to unfamiliarity with Canadian conditions or, in the case of home-bred critics to the influence of propaganda or the mere difficulty of arriving at facts. Such a body of adverse comment has got to be taken seriously, and in this discussion an attempt will be made to analyse its principal points both in order to see more clearly where we really stand and also to draw whatever lessons may seem to be of value.

An article that has recently been published in the Empire Forestry Journal suggests a good starting point for this study ${ }^{1}$. In this article Mr. C. G. Trevor, C.I.E., draws from the report of the Director of Forestry for 1932-33, taken in conjunction with the pamphlet Forest Facts that is also published by the Department of the Interior, the conclusion that "very little progress in the fundamental requirements of forest management seems to have been made since I had the pleasure of seeing the magnificent forest estate of Canada in 1923." (Mr. Trevor, of course, alludes to the Second British Empire Forestry Conference, which was held in Canada in 1923). This article being just such a piece of authoritative advice as compels careful attention, and the Conference of 1923 having also recorded its considered opinions on some of our problems in the reports of its committees on Silviculture and Fire Protection, it will be of great interest to review the recommendations of these committees as well as the suggestions made by Mr. Trevor himself in order to see whether or how far they have been put into effect in the years that have elapsed since the Conference, or could or ought to be put into effect in the future. (Many of these recommendations must, however, be considered as applying primarily to the various governments, which are concerned more directly than the industrial forest operators with the questions concerned.)

The principal recommendations may be grouped into four classes, as concerning-1. Land classification and the formation of forest reserves: 2. Fire

\footnotetext{
I"Some Reflections on Forestry in Canada" by C. G. Trevor, C.I.E., Inspector-General of Forests, India. Empire Forestry Journal, Vol. 14, No. 1, 1935; also in "The Forestry Chronicle," Vol. X, No. 4, December 1934. pp. 192-195.
} 
protection: 3. Sustained yield, inventory, and working plans: 4. Silviculture, including research. These will be discussed in order.

\section{LAND CLASSIFICATION AND THE FORMATION OF FOREST RESERVES}

This is of course a matter which is solely in the competence of the Provincial Governments. The forest-using industries cannot be considered to have any responsibility in connection with it except insofar as expressions of their opinions and desires may be supposed to weigh with the Governments concerned. Nevertheless, it is worth remarking that the policy of reserving absolute forest land for forest purposes has made considerable headway during the past ten years, seeing that the Province of Quebec has constituted up to date some 36,945 square miles of forest reserves of all categories-this figure including long-term forest reserves intended for the supply of raw material to large industries, reserves of shorter terms on licensed land in colonization districts that is itself uncultivable, and townships forest reserves to supply the needs of the rural population.

As far as what may be called the "indirect" responsibility of the forestusing industries is concerned, it is sufficient to point out that the only or ganization which represents the interests of timber-license holders as such in Eastern Canada has constantly pressed for the classification of land on a large scale and the formation of forest reserves, and that a considerable part of the total area mentioned above has been placed in reserve at its instance.

It thus appears that the desirability of confining colonization to agricultural districts and of reserving absolute forest land for timber production is quite fully recognized by all concerned, and that while very much more should still be done along these lines, some definite progress has been made since 1923.

\section{FIRE PROTECTION}

The responsibility for protecting the forests against fire rests solely with the Provincial Government in Ontario, New Brunswick and Nova Scotia, but in Quebec is shared by the Government and the license-holders-the latter being required to protect their own limits, though the measures which they take to that end are always subject to the Government's approval.

Now, while everyone concerned will admit that fire-protection is a very long way from being perfect, we may also be fully confident that the situation has improved very materially since 1923 . This fact was recognized by the third British Empire Forestry Conference, held in Australia in 1928, as appears from the following passage taken from its Summary Report and 
Resolutions:- "The Canadian situation shows considerable improvement since the last Conference held in that country in 1923, particularly with reference to more favourable public sentiment regarding the necessity of preventing forest fires." And while it may be unsafe to quote decreased annual figures for the areas burned, as these are so much influenced by the incidence of dangerous weather conditions, it is fair to point to the increase in normal expenditure on fire-protection work since 1923 as shown, for instance, by the published figures of the Government's budget estimates. ${ }^{2}$

Granted then that things are better than they were in 1923, it will still be worth while to see how far the detailed recommendations of the Conference can help towards a further improvement. In the first place we are again brought up against the question of forest reserves, the exclusion of settlers from forest lands being, as everyone knows, the only sure safeguard against the conflagrations which are certain to be started sooner or later in the process of land clearance. This matter is, in fact, even more important now than it was in 1923, owing to the great impetus which settlement has received in the last few years as a result of the economic depression. The needs of fire-protection must consequently be regarded as an additional argument in favour of the extension of forest reserves and this recommendation of the Conference should receive proportionate attention.

In the second place comes an allusion to the necessity of public education and the creation of a general public opinion favourable to fire prevention by means of propaganda directed particularly to the young. Nobody who has observed the excellent results of the Canadian Forestry Association's lecture campaigns in the country districts can fail to recognize the value of such educational work, and in fact, as has been said above, the improvement in the public attitude to conservation was remarked upon by the Conference of 1928. Had the improvements continued progressively until now, or had the standard then reached even been maintained, it would be possible to feel fairly well satisfied on this score; however, in point of actual fact not only have funds for intensive propaganda work been lacking since the depression became acute but the need for such work has been very much increased owing to the influx into the colonization areas during the same period of large numbers of settlers of a new type, having little or no experience of life in the woods or appreciation of their responsibilities towards their neighbours, the license-holders, or the public at large. Consequently the recommendation

\footnotetext{
2Large figures for supplementary estimates, or even large figures for total expenditure which include funds derived from the supplementary estimates should not be considered in this connection, as they may indicate insufficient normal preventive work leading to increased emergency expenditure or fire-fighting in the course of the season.
} 
made by the Conference on this point probably possesses quite as much force to-day as it did in 1923.

In the third place we find a strong recommendation in favour of slash. disposal. The Committee on Fire Protection held that slash-disposal on log. ging operations would have to be secured before "adequate" fire-protection could be hoped for, and recommended that the Governments of Ontario, Quebec and New Brunswick should take joint action to equalize costs between competitive operations. Now while everyone recognizes the tremendous hazard created in old cutting areas by heavy unrotted slash, it is equally to be remarked that the agitation in favour of slash-disposal which was going on even within the trade ten to twelve years ago, seems to have completely sub. sided; and as far as the present writer knows this has been due simply to the unfavourable results of the experiments in slash-disposal which were carried out by numerous companies at that time. In addition to the very high costs that were entailed, experiments made it clear that the character of the slash varied so much from one operation to another-in accordance with minimum diameter of logs taken, type and density of stand, and so forthas to render general conclusions and general rules impossible; and the further difficulties presented by windfalls and natural debris were also quickly realized when the controversy was removed from the council-chamber to the woods. We shall, therefore, probably be safe in passing over this recommendation insofar as it applies to the disposal of all slash, while bearing in mind that exceptional conditions might well make it worth while to dispose of a certain amount of slash in specially selected places. (It may also be remarked in pas. sing that the condition which the Conference of 1923 regarded as necessary to make general slash-disposal possible economically, namely joint legislative action by all the Eastern Provinces, is never likely to be realized in practice.)

As regards the Committee's detailed suggestions for "Fire Control" the situation seems to be a good deal less black than it is painted, in Quebec at least. The law of that Province gives fire inspectors very full emergency powers, including that of conscripting fire-fighters at a set rate of pay; it also forbids the lighting of fires in or near the forest unless a permit has been issued, and defines pretty clearly the conditions under which such a permit may be issued as well as the duties of fire-rangers in connection with settlers' fires. In fact, there is comparatively little to criticize in the fire-protection laws of Quebec as they stand on paper. Finally, the uses and limitations of aircraft in fire-protection are very much better understood now than they were in 1923, while the development of commercial flying has really quite altered the complexion of the question which the Conference then considered. 


\section{SUSTAINED YIELD, INVENTORY AND WORKING PLAN}

When we turn to these subjects the opinions of our external advisors begin to read strangely. The Conference of 1923 pointed out, quite rightly, that co-operation between the license-holders and the Governments was absolutely necessary for proper silvicultural management, and considered that if the Governments conceded something to the operators (presumably by the formation of forest reserves), the operators "should be prepared also to help in securing the permanence of the industry." Mr. Trevor again, in the article which has already been quoted, finds it "difficult to believe that these interests (i.e. the lumber and pulpwood operators) cannot be reconciled to the principles of the sustained annual yield and a working plan." It is thus pretty clear that the position of the pulpwood operators under the laws and regulations of the Province of Quebec has not been understood abroad; and the same may be said of the lumbermen insofar as they wish to cut spruce of less than twelve inches or balsam less than seven inches in diameter on the stump. For so far from being able to turn a deaf ear to the Government's wishes, and to cut "what they like, where they like, and when they like" (to quote an expression that the writer has lately seen in print), the licenseholders are actually forbidden to cut any trees of less than the dimensions that have just been stated unless special authorization has been granted them by order-in-council. Moreover, in order to obtain such authorization it is necessary for the license-holder concerned to produce a working plan ${ }^{3}$ "based" (in the words of the statute) "on a proper inventory and made according to the instructions of the Minister of Lands and Forests." In cases where working. plans cannot be produced immediately the license-holders are allowed to submit instead their inventory-data accompanied by a rough outline of their proposals for management, this procedure being repeated annually. It is thus obvious enough that pulpwood operators in Quebec are not in a position to do anything but cu-operate with the Government in the matter of inventories and working plans; and consequently if the Government does not eventually succeed in restricting the annual cut to $80 \%$ of the increment in accordance with its declared policy, and of perpetuating the forests on Crown lands, the reason will have to be looked for elsewhere than in any dislike on the part of license-holders to the principle of sustained yield.

It may be of interest to remark here that at the date of writing, licenseholders in the Province of Quebec have submitted working'plans covering 25,000 square miles and inventories covering 43,500 square miles, out of a total area of 78,000 square miles held under timber-license by pulpwood special provisions. 
operators. These figures indicate not only that the first steps in forest management, for which Mr. Trevor calls in his article in the Empire Forestry Journal, have already been taken but that quite respectable progress has been made.

\section{SILVICULTURE, INCLUDING RESEARCH}

Our knowledge of the silvicultural characteristics of the Eastern Canadian woodlands has been so much increased during the last twelve years by the inventory work to which allusion has just been made, and the practical requirements of large commercial operations have now come to be so much better understood, that some of the recommendations of the Conference under this head are no longer fully applicable. It still remains true, of course, as the Committee on Silviculture stated, that the problems of Canadian silviculture only differ in degree and not in general character from those of other countries in which systematic silviculture is successfully practised, and that consequently an exclusively Canadian technique will not necessarily have to be worked out. Nor wrill anyone question the Committee's condemnation of general diameter-limits fixed by law when they are used as a silvicultural measure, nor yet its plea for continued research both in pure silviculture and in the commercial application of whatever lessons research may teach. But on the other hand the writer believes that a much less pessimistic view than that of the Committee on Silviculture may now be taken regarding the prospects of natural regeneration in the pulpwood forests of the North-East. Growth studies made for inventory purposes have shown that the mixture of spruce, balsam, paper-birch and poplar, which forms the bulk of the stand in those areas which lie beyond the natural limit of the tolerant hard-woods, have normally come into being in the past as the result of fires, the conifers having come in under the birch and poplar and gradually grown through them at the cost of no more than some more or less serious retardation in their rate of growth. The practice of removing all the conifers in areas where coniferous growth is plentiful, while leaving the paper-birch standing, may therefore probably be regarded as silviculturally blameless, and, while the removal of the birch would unquestionably shorten the rotation, there is no reason to think that this operation is actually necessary to secure the perpetuation of coniferous growth. There is also some reason for supposing that the proportion of spruce in the mixture increases with the age of the stand, and that consequently the huge preponderance of balsam that is normal everywhere in the advance-growth need not necessarily be taken as presaging a serious falling off in the proportion of spruce that will be found in the final crop.

We may therefore be confident that the method of treating forests of this 
type which is now approved by the Quebec Government-namely, the removal of the mature coniferous crop in one operation in areas where advance growth is present and the exclusion of operations from the immature stands which are deficient in advance-growth-represents a considerable improvement on anything that the Conference members appear to have seen in 1923. At any rate, stands which are cut on this principle may be expected from the scope of a statement made by the Committee on Silviculture to the effect that in the spruce-balsam forests of Ontario, Quebec and the Maritimes that were under operation for pulpwood as well as for sawlogs, the system of logging employed was such that "practically no regeneration of the more valuable species" followed.

An equally optimistic view cannot unfortunately be taken of the prog. ress made in handling mixed stands in which the hardwood element is tolerant of shade. After twelve years we still have no such demand for yellow birch and maple lumber as is required to encourage the exploitation of these species on a really large scale, and failing such large-scale demand for the number of these species, little practical result cound be looked for even if the problem of their extraction by water, which the Conference of 1923 recommended as a subject for research, were satisfactorily solved. (It may be mentioned here that a very important set of experiments in the flotation of hardwoods has been carried out by several pulp and paper companies in Eastern Canada in collaboration with the Canadian Pulp and Paper Association and the Forest Products Laboratories of Canada; also that certain operators have investigated this matter on their own account.) The killing of hardwoods on the stump, as a substitute for commercial exploitation has also been looked into and the limitations as well as the possible utility of girdling are now pretty well known. In spite of all these efforts, and of an extensive experiment in cutting methods that was set on foot some years ago by the Dominion Forestry Branch in collaboration with a Quebec operator, the problem of treating hardwoods seems to be no nearer solution and one is left with the suspicion that there may actually be no agent except fire by which, if at all, these areas could be brought into a suitable condition to support coniferous forest. Fortunately this problem is not of very great importance to the principal pulp. wood operators, seeing that this type of forest occupies only a small proportion of their limits, and that colonization-whether permanent or temporary -is likely in the long run to sweep over most of the districts in which tolerant hardwoods thrive.

Planting is another question which calls for mention here as the Conference of 1923 recommended the planting of waste lands as a supplement to 
the intelligent management of existing forests, which it recognized as constituting the main source of future supplies. It will be enough however to remark that funds for this purpose would be difficult or impossible to obtain in the present condition of the pulp and paper industry; that no prudent person would in any case plant on licensed lands; and that the recent collapse under financial stresses of a far-reaching and well-planned scheme of planting on privately-owned land is likely to discourage the repetition of any such attempt even if all the conditions appeared to be favourable to it. Planting, in fact, may be ruled out as falling within the competence of Governments only. ${ }^{4}$

Research is likewise essentially a Government function, but the contributions to knowledge that have been made by the commercial operators, not only through the important studies which have been mentioned above but also through a great deal of miscellaneous work done by their forestry staffs in the course of their duties, have been so large that this subject must receive some mention, and this is all the more necessary because the language of $\mathrm{Mr}$. Trevor's article suggests that outside observers believe our lack of silvicultural knowledge to be really profound. Mr. Trevor quotes from the report of the Director of Forestry for 1923, to the effect that information must be gathered as to the rate of growth of various types and classes of forest and the most practical means of obtaining natural regeneration, and that without this knowledge it is impossible for Governments or operators to make intelligent plans for managing their timber lands. He evidently understands these pas. sages to imply that no such information has as yet been gathered, and that intelligent plans cannot in consequence be made; this is made clear by the stress which he lays on the ease with which some information of this kind could be obtained, and by his suggestion that one season spent on ring counting would give a perfectly satisfactory indication of a suitable length of rotation for the production of pulpwood in Quebec. It is greatly to be regretted that foresters in other countries should be left under the impression that we are still at the stage of crude and hasty stem-analysis, and they will certainly not continue in this misapprehension when they consider the volume of the growth-studies entailed by the Quebec inventories alone. Further examples may be found in the volume tables and other data that have been published from time to time by the Dominion Forestry Branch, or in the experimental work of the Canadian Pulp and Paper Association. ${ }^{5}$ Indeed, while nobody

4Planting is actually being pushed forward quite actively by the various Forest Services, and farmers are also being encouraged to plant on their lands.

5The early publication by the Provincial Governments of the results of much work done on Crown lands by their own and the licence-holders' personnel, which is now lying in departmental files, is much to be hoped for. 
wishes to disguise the backwardness of Canadian forestry technique in comparison with that of more highly developed countries, there is nevertheless some ground for maintaining that we already possess more knowledge than artificial limitations permit us to apply in large pulpwood operations; for where thinning, planting, sowing, the removal of unwanted species, and even the marking of trees for individual felling, are all ruled out by economic necessities, no very great scope remains for advanced silvicultural practice. But leaving this last consideration aside we may feel confident that research is making real progress, and that in this respect also a valuable recommendation of the Conference of 1923 is being followed up.

The four main subjects have now been discussed insofar as space permits, and the writer believes that he has made out a case for modern Canadian forestry that is fully justified on the facts. There is one final matter, however, which requires a passing notice, and that is the common belief that the forests are somehow melting away under fires, pests, devastation, and disasters of every kind and that unfavourable changes in the climate are to be looked for sooner or later as a result. The more picturesque developments of this theory are connected with the propaganda campaigns of the late $\mathrm{Mr}$. F. J. D. Barnjum; but the Empire Conference also, visiting Canada as it did at a time when the damage done by the great budworm outbreak was still appallingly obvious and in a summer that brought some of the worst fires within living memory, naturally received a disquieting impression that is reflected in the language of its report. Fears on the score of such catastrophes having thus gained wide publicity on both sides of the Atlantic it is desirable to put forward some considerations which tend to deflate to a certain extent the more alarmist statements that are sometimes seen in the press.

Nobody, of course, can deny that the budworm destroyed an immense volume of timber of which only a small proportion was ever salvaged, but there is another side to this picture which escapes the notice of persons who are not foresters. Everyone who is familiar with actual conditions in the woods, knows that young crops of great richness are now growing up all over the devastated areas; and thus, while the value of the mature timber has undoubtedly been lost to its owners, the forest itself is seen, if a really long view be taken, not to have suffered any loss of productive power, except insofar as the new stands may turn out to contain more balsam and less spruce than the old ones. In fact, these attacks of budworm, spruce sawfly, or hemlock looper are really no more than natural substitutes for the fellings that should have been made in the over-mature stands, and as such need not be regarded as likely to have permanently disastrous effects. 
One may even go so far as to suggest that the danger of fire itself is open to exaggeration. Our losses by fire are admittedly serious enough, but never theless there is nothing at all to be gained by discounting the very great improvements in protective organization and methods that have taken place since 1923. (The decrease in the average burned will or will not be accepted as another encouraging sign according as it is attributed mainly to improved protection or more favourable seasons.) It is also worth while to ask how much of the areas burned in the neighbourhood of settlements could ever have been saved for sustained forest production; for if land is destined in any case to pass into settler's hands, the premature burning of the timber makes no difference to our ultimate forest resources, however, annoying the loss may be to present or prospective owners. Again, it must be remembered that a fire can be followed under favourable conditions, and often is so followed, by perfectly satisfactory regeneration, and that the new stand regularly contains a much. higher percentage of spruce than those which are regenerated by cutting or which follow insect attack.

As regards the changes in climate and other unfavourable results that are sometimes foretold as likely to result from the cutting-down of forests, it will be enough to say that experiments made both in Europe and the United States have failed to show that forests have any appreciable effect on rainfall whatsoever. Once the rain has fallen its rate of run-off unto the rivers is of course affected very powerfully by the presence or absence of forests, and it is because alternate floods and droughts are experienced in watersheds that have been more or less completely cleared for agriculture that alarmists are able to point to such occurrences in support of their propaganda. However, the fact of streamflow being upset in this way by the natural expansion of agriculture has no real bearing at all on the subject now under consideration, and the popular expectation of disaster is once more seen to be unfounded. 